\title{
How to screen for COVID-19 in a dedicated fever clinics: experiences from China
}

Jing Liu ${ }^{1}$, Yuankai $\mathrm{Wu}^{1}$, Shuru Chen ${ }^{1}$, Zhiliang $\mathrm{Gao}^{1}$, and Yutian Chong ${ }^{1}$

${ }^{1}$ Third Affiliated Hospital of Sun Yat-Sen University

April 28, 2020

\begin{abstract}
$\mathrm{n} / \mathrm{a}$

Hosted file

manuscript0410+Jing Liu V6.doc available at https://authorea.com/users/313508/articles/443988how-to-screen-for-covid-19-in-a-dedicated-fever-clinics-experiences-from-china
\end{abstract}



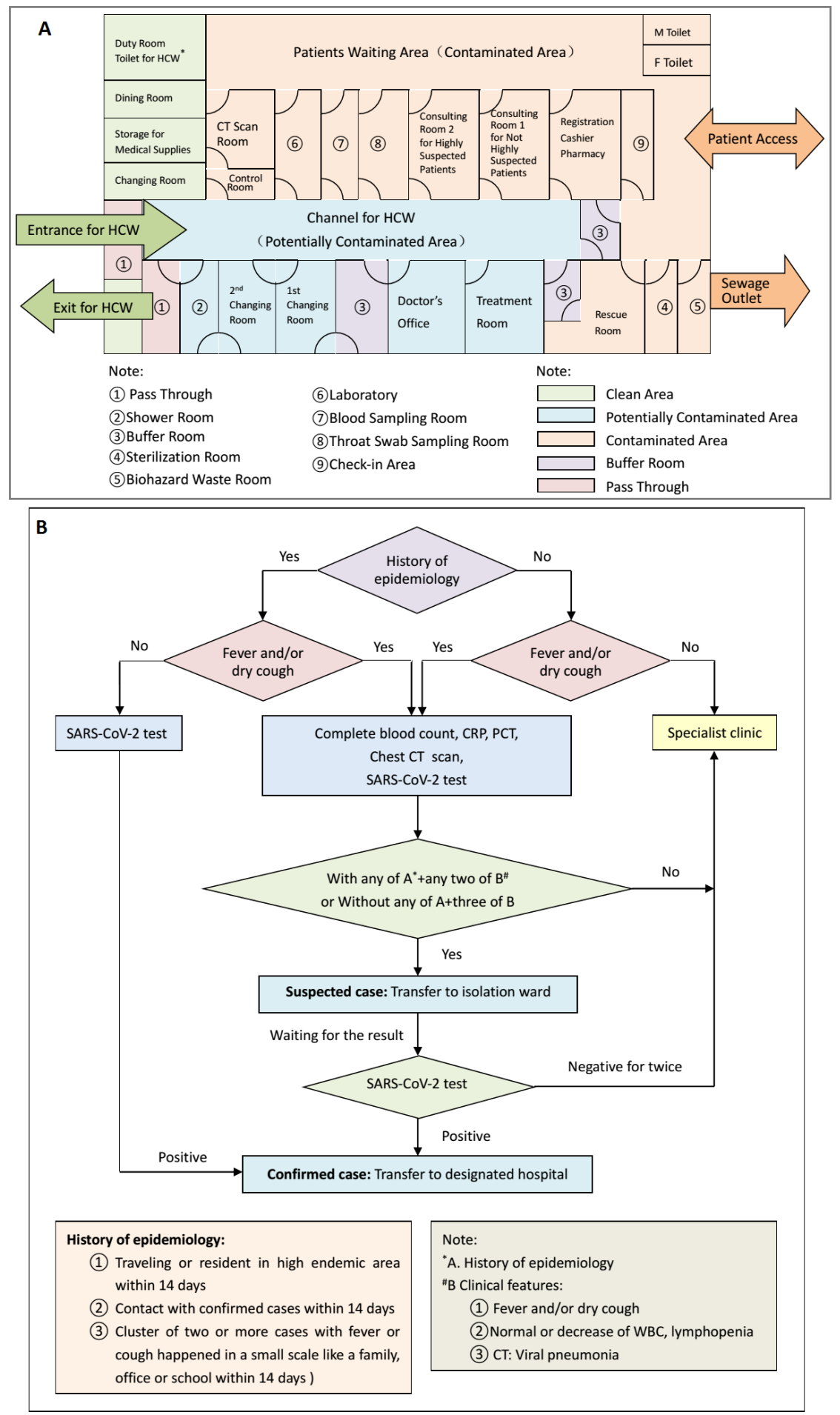